\title{
Antenatal corticosteroids and the renin-angiotensin- aldosterone system in adolescents born preterm
}

\author{
Andrew M. South ${ }^{1,2}$, Patricia A. Nixon ${ }^{1,3}$, Mark C. Chappell ${ }^{2,4}$, Debra I. Diz ${ }^{2,4}$, Gregory B. Russell ${ }^{5}$, Beverly M. Snively ${ }^{5}$, \\ Hossam A. Shaltout ${ }^{2,6}$, James C. Rose ${ }^{6}$, T. Michael O'Shea ${ }^{2,7}$ and Lisa K. Washburn ${ }^{1,2}$
}

BACKGROUND: Antenatal corticosteroid (ANCS) treatment hastens fetal lung maturity and improves survival of premature infants, but the long-term effects of ANCS are not welldescribed. Animal models suggest that ANCS increases the risk of cardiovascular disease through programmed changes in the renin-angiotensin (Ang)-aldosterone system (RAAS). We hypothesized that ANCS exposure alters the RAAS in adolescents born prematurely.

METHODS: A cohort of 173 adolescents born prematurely was evaluated, of whom 92 were exposed to ANCS. We measured plasma and urine Ang II and Ang-(1-7) and calculated Ang II/Ang-(1-7) ratios. We used general linear regression models to estimate the difference in the RAAS between the ANCS-exposed and unexposed groups, adjusting for confounding variables.

RESULTS: In unadjusted analyses, and after adjustment for sex, race, and maternal hypertension, ANCS exposure was associated with increased urinary Ang II/Ang-(1-7) (estimate 0.27 (95\% Cl 0.03, 0.5), $P=0.03)$, increased plasma Ang-(1-7) (0.66 $(0.26,1.07), P=0.002)$, and decreased plasma Ang II/Ang$(1-7)(-0.48(-0.91,-0.06), P=0.03)$.

CONCLUSION: These alterations indicate an imbalance in the urinary RAAS, promoting the actions of Ang $\|$ at the expense of Ang-(1-7), which over time may increase the risk of renal inflammation and fibrosis and ultimately hypertension and renal disease.

A ntenatal corticosteroids (ANCS), given to pregnant women expected to deliver prematurely to accelerate fetal lung maturity, increases survival and improves outcomes in the offspring, but the long-term effects of ANCS are not wellcharacterized (1-3). Data from preclinical models that simulate human exposure suggest that ANCS may increase the risk for hypertension (HTN) and cardiovascular disease $(4,5)$. The increased risk may be mediated in part by chronic dysregulation of the renin-angiotensin (Ang)-aldosterone system
(RAAS), leading to increased renal and cardiovascular disease in adulthood $(6,7)$. Human studies offer conflicting conclusions regarding relationships between ANCS exposure and cardiovascular outcomes in adolescents and young adults and have not evaluated the effect of ANCS exposure on the RAAS (8-12).

The RAAS includes the Ang-converting enzyme (ACE)/ Ang II pathway and the ACE2/Ang-(1-7) pathway, is important in renal and cardiovascular development, and is subject to developmental changes early in life $(13,14)$. Ang II is a vasoconstrictor, enhances sodium retention directly and through stimulation of aldosterone, and promotes inflammation and fibrosis, while Ang-(1-7) has variable effects on sodium transport and glomerular filtration and has anti-inflammatory and anti-fibrotic effects in numerous organ systems, including the kidney (6,15-19). An altered RAAS is associated with adverse health outcomes, including HTN and chronic kidney disease (20). RAAS components measured in the urine are markers of the intrarenal RAAS (21-23). We measured RAAS components in adolescents born prematurely to evaluate the hypothesis that ANCS exposure is associated with long-term alteration of the balance between Ang II and Ang-(1-7) in plasma and urine.

\section{RESULTS}

\section{Study Population}

Reflective of the larger ANCS study's design, approximately half the study sample was born to mothers who received ANCS (53\%) (Table 1). The majority of subjects were female $(55 \%)$, $43 \%$ were black, and $35 \%$ were overweight/obese at 14 y of age. Maternal HTN complicated $36 \%$ of pregnancies. Blacks were less likely to receive ANCS. The ANCS group had a higher rate of maternal HTN and was taller.

\section{ANCS Exposure and Urinary RAAS}

There were no differences in Ang II, Ang II/creatinine, Ang(1-7), or Ang-(1-7)/creatinine (Table 1). Ang II/Ang-(1-7)

\footnotetext{
'Department of Pediatrics, Wake Forest School of Medicine, Winston Salem, North Carolina; ${ }^{2}$ Hypertension and Vascular Research Center, Wake Forest School of Medicine, Winston Salem, North Carolina; ${ }^{3}$ Department of Health and Exercise Science, Wake Forest University, Winston Salem, North Carolina; ${ }^{4}$ Department of Surgery, Wake Forest School of Medicine, Winston Salem, North Carolina; ${ }^{5}$ Department of Biostatistical Sciences, Wake Forest School of Medicine, Winston Salem, North Carolina; ${ }^{6}$ Department of Obstetrics and Gynecology, Wake Forest School of Medicine, Winston Salem, North Carolina; ${ }^{7}$ Department of Pediatrics, University of North Carolina School of Medicine, Chapel Hill, North Carolina. Correspondence: Andrew M. South (asouth@wakehealth.edu)

Received 24 May 2016; accepted 20 July 2016; advance online publication 5 October 2016. doi:10.1038/pr.2016.179
} 
Table 1. Clinical characteristics and the renin-angiotensin-aldosterone system profile at $14 \mathrm{y}$

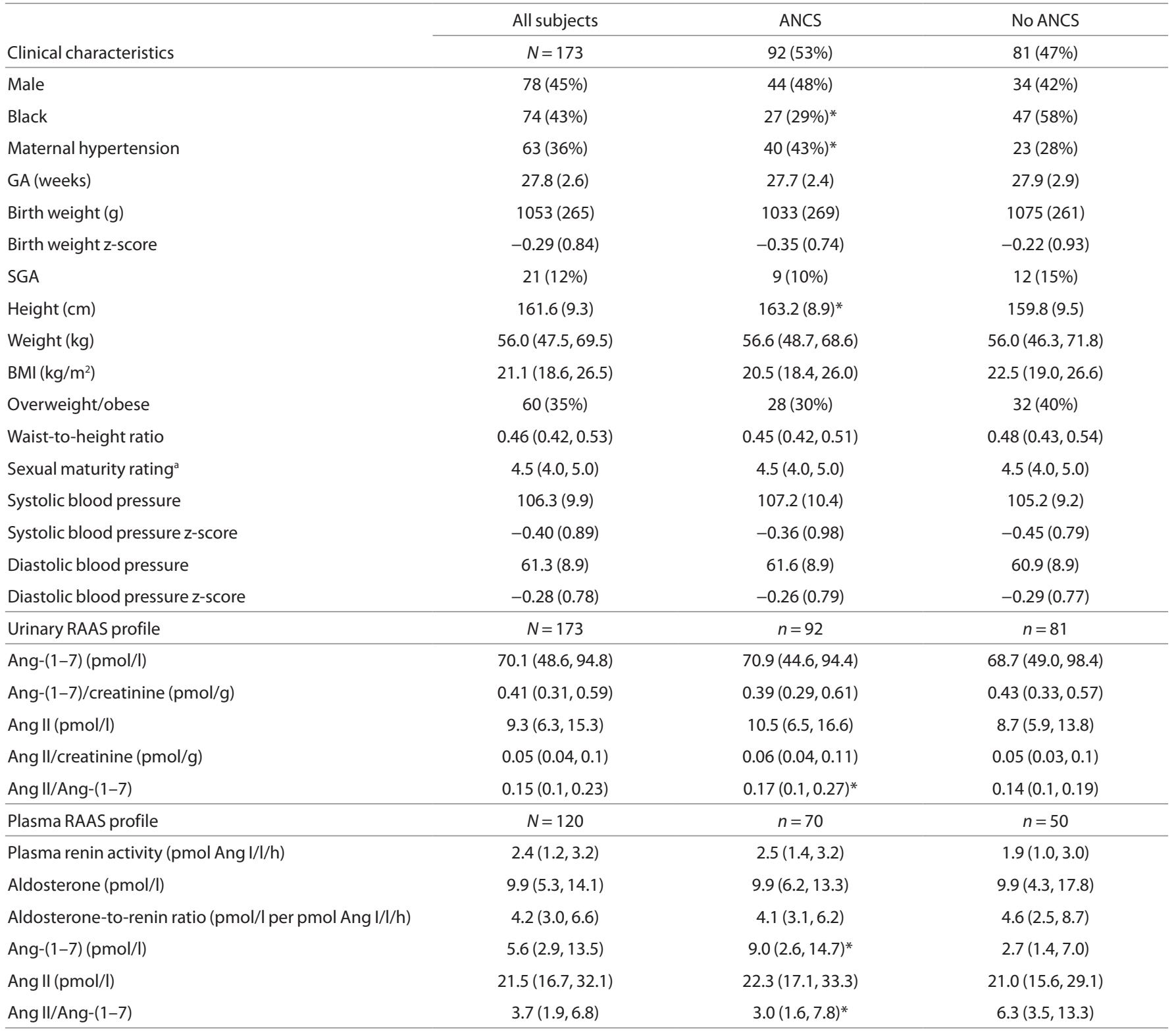

$N(\%)$, mean (SD), median (IQR). a $n=154$. *Denotes significant difference between groups with $P<0.05$ by chi-square test, $t$-test, or Wilcoxon Rank-Sum test. ANCS, antenatal corticosteroids; RAAS, renin-angiotensin (Ang)-aldosterone system; SGA, small for gestational age.

was higher in the ANCS group and this difference persisted when adjusting for race, sex, and maternal HTN (estimate 0.27 (95\% CI 0.03, 0.5), $P=0.03$ ) (Table 2).

\section{ANCS Exposure and Plasma RAAS}

There were no differences in plasma renin activity, aldosterone, aldosterone-to-renin ratio (ARR), or Ang II (Table 1). The ANCS group had higher plasma Ang-(1-7) and lower Ang II/ Ang-(1-7), and these differences persisted when adjusted for race, sex, and maternal HTN (Ang-(1-7): $0.66(0.26,1.07)$, $P=0.002$; Ang II/Ang-(1-7): $-0.48(-0.91,-0.06), P=0.03)$ (Table 2, Figure 1). The associations of ANCS with higher plasma Ang-(1-7) and lower Ang II/Ang-(1-7) were stronger among black study participants (Ang-(1-7): $1.13(0.61,1.66)$,
$P<0.001$; Ang II/Ang-(1-7): $-0.91(-1.48,-0.33), P=0.003)$ (Figure 2).

Although log-transformed waist-to-height ratio was associated with both plasma Ang-(1-7) and Ang II/Ang-(1-7) $(-1.44$ (-2.65, -0.23), $P=0.02 ; 2.26(1.04,3.47), P<0.001)$, adding waist-to-height ratio to the regression models did not substantially alter the association between ANCS and plasma RAAS.

\section{DISCUSSION}

Among adolescents born prematurely, ANCS exposure was associated with increased urinary Ang II/Ang-(1-7), increased plasma Ang-(1-7), and decreased plasma Ang II/Ang-(1-7). The increased urinary Ang II/Ang-(1-7) among preterm 
Articles | Southetal.

Table 2. Relationship between antenatal corticosteroid exposure and the renin-angiotensin (Ang)-aldosterone system

\begin{tabular}{|c|c|c|c|c|c|c|c|}
\hline & \multicolumn{2}{|c|}{ Unadjusted } & \multicolumn{2}{|c|}{ Adjusted $^{a}$} & \multicolumn{3}{|c|}{ Stratified $^{\text {a }}$} \\
\hline & Estimate $(95 \% \mathrm{Cl})$ & $P$ value & Estimate $(95 \% \mathrm{Cl})$ & $P$ value & & Estimate $(95 \% \mathrm{Cl})$ & $P$ value \\
\hline Urine Ang II/Ang-(1-7) & $0.26(0.04,0.48)$ & 0.02 & $0.27(0.03,0.5)$ & 0.03 & - & - & - \\
\hline Plasma Ang II/Ang-(1-7) & & & & & Non-Black ${ }^{c}$ & $-0.21(-0.78,0.36)$ & 0.46 \\
\hline Plasma Ang-(1-7) & $0.65(0.28,1.02)$ & $<0.001$ & $0.66(0.26,1.07)$ & 0.002 & Black $^{b}$ & $1.13(0.61,1.66)$ & $<0.001$ \\
\hline
\end{tabular}

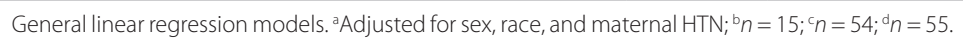

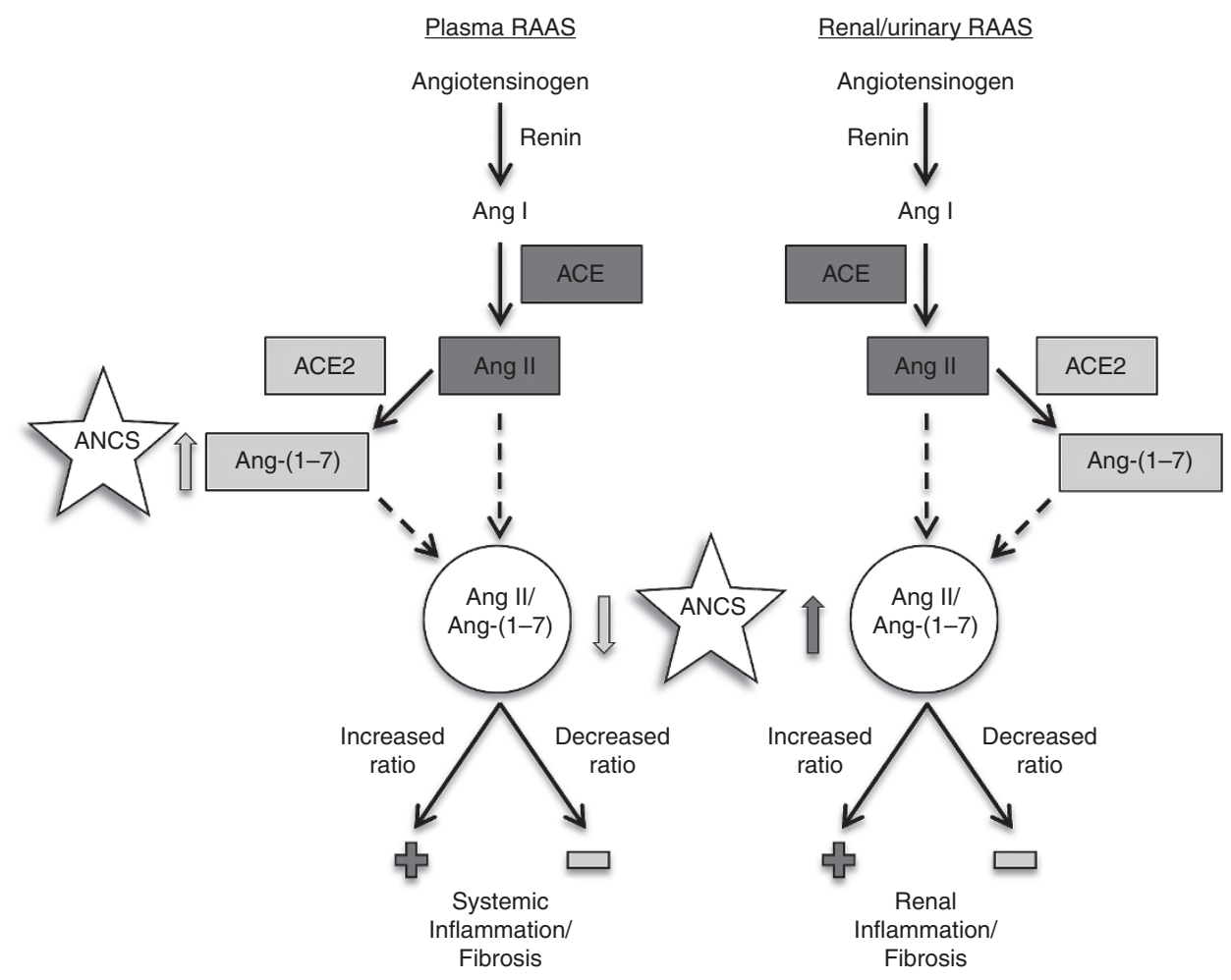

Figure 1. Relationship between antenatal corticosteroids (ANCS) and renin-angiotensin (Ang)-aldosterone system (RAAS). Gray arrows indicate direction of association with the RAAS: dark gray indicates upregulation of Ang II and light gray indicates upregulation of Ang-(1-7).

adolescents exposed to ANCS may be due to a higher renal (urinary) Ang II. This shift in the kidney, toward Ang II and away from Ang-(1-7), is consistent with the finding that offspring of pregnant ewes exposed to clinically relevant doses of ANCS (betamethasone given at 0.6 gestation: the equivalent of about $24 \mathrm{wk}$ gestation in humans) develop alterations in the renal RAAS, decreased renal function, and elevated blood pressure as adults. RAAS alterations include attenuated responses to Ang-(1-7), enhanced responses to Ang II, increased expression of the Ang II type 1 receptor, increased serum ACE activity, decreased serum ACE2 activity, and decreased proximal tubular ACE2 activity and expression. Together these alterations indicate an imbalance in the RAAS which promotes the actions of Ang II at the expense of Ang-(1-7) $(6,7,24,25)$.

Over time, elevated renal Ang II levels could increase the risk for renal inflammation and fibrosis and may lead to HTN and renal disease (26). This mechanism could accentuate other perinatal renal insults such as ischemia and nephrotoxic exposure $(21,27)$. In contrast to RAAS alterations in urine, plasma levels of Ang-(1-7) were higher among ANCS-exposed adolescents, which might serve to attenuate the physiologic effects of an elevated Ang II to Ang-(1-7) ratio in the kidney. A potential explanation for this finding is that it may reflect a compensatory upregulation to counteract further inflammation and fibrosis by Ang II as ACE2 expression and elevated Ang-(1-7) levels are evident in several pathologic states $(28,29)$. ANCS exposure could also directly lead to increased systemic or vascular ACE2/Ang-(1-7) pathway activity.

Consistent with data showing obesity is associated with an upregulated ACE/Ang II pathway (30), we found that waistto-height ratio, a measure of central adiposity, was associated with decreased plasma Ang-(1-7) and increased plasma Ang II/Ang-(1-7). Obesity-driven RAAS dysregulation is associated with inflammation, insulin resistance, and metabolic 

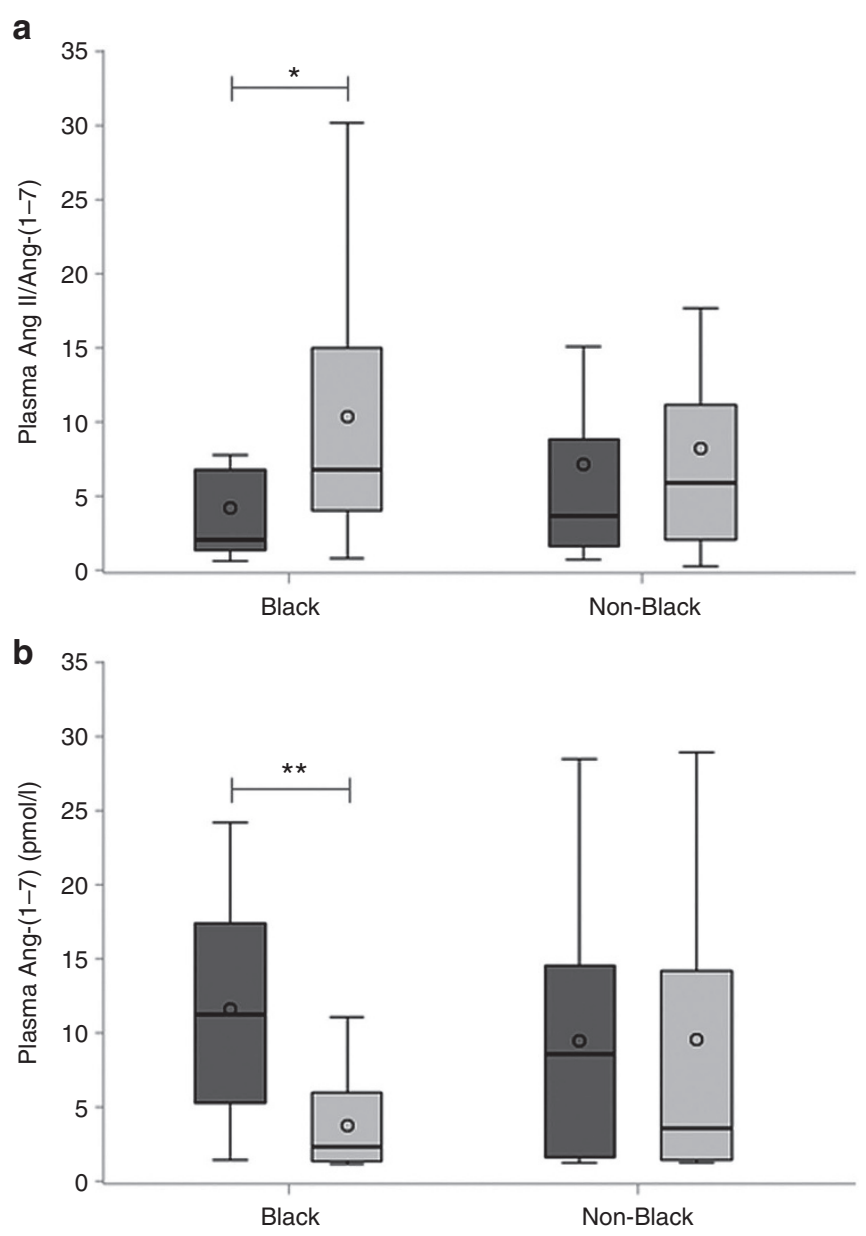

Figure 2. ANCS and renin-angiotensin (Ang)-aldosterone system stratified by race. (a) Plasma Ang II/Ang-(1-7). (b) Plasma Ang-(1-7). ${ }^{*} P=0.002$, ${ }^{*} P<0.001$. ANCS $=$ dark gray; no ANCS = light gray. Bar denotes median, circle denotes mean, box indicates IQR, and whiskers include $\leq 1.5 \times \mathrm{IQR}$. Between-group comparisons by Wilcoxon Rank-Sum test. ANCS, antenatal corticosteroids.

disease (31). Racial differences in plasma renin activity and aldosterone are well-documented. Our finding that associations between ANCS and the RAAS were stronger among black study participants suggests the possibility that long-term effects of ANCS might differ for blacks and non-blacks.

Our study is limited by the nonrandomized allocation of the exposure (ANCS), leaving open the possibility of confounding due to factors we did not measure. We could not fully account for all the potential factors that influence the RAAS, such as genetic influences and dietary variability. Further, we lack measurements of RAAS enzymatic activity, specifically ACE and ACE2, which could better characterize the profiles of the ACE/Ang II and ACE2/Ang-(1-7) pathways in this cohort.

In conclusion, in a cohort of adolescents born prematurely, ANCS exposure was associated with alterations in the RAAS, specifically increased urinary Ang II/Ang-(1-7), increased plasma Ang-(1-7), and decreased plasma Ang II/Ang-(1-7). An altered systemic and intrarenal RAAS may modify an individual's cardiovascular risk profile and negatively impact kidney function later in life.

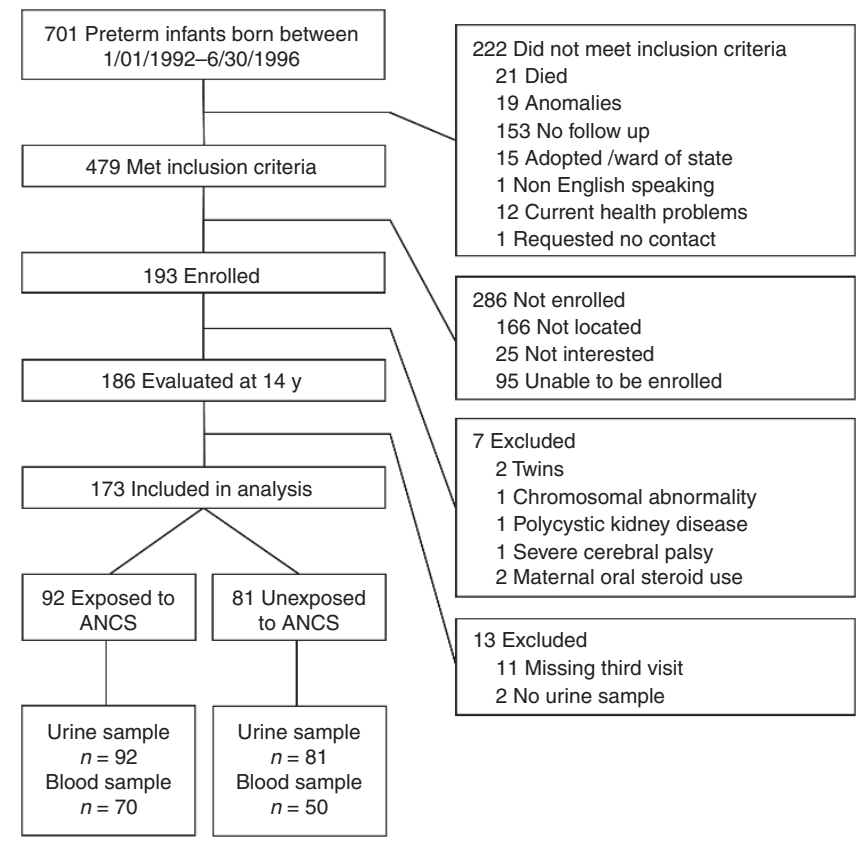

Figure 3. Study participant flow diagram.

\section{METHODS \\ Study Participants}

Study participants were recruited from among living members of a premature birth cohort of 193 patients born between 1 January 1992 and 30 June 1996 at a regional perinatal center (Forsyth Medical Center in Winston Salem, NC). This cohort included (i) children with whom we had contact through at least $1 \mathrm{y}$ of age, (ii) were not wards of the state, and (iii) were successfully contacted at $14 \mathrm{y}$ of age. Sixty-two percent of those contacted were enrolled $(n=193)$. Of the 193 cohort subjects, seven were excluded from the analysis (two were twins, three had congenital anomalies, and two had maternal oral steroid use). The members of the cohort were evaluated at $14 \mathrm{y}$ of age as part of a larger study of ANCS exposure and cardiovascular and metabolic outcomes among preterm adolescents (Figure 3). We report the measurements made at the third study visit, at which 173 subjects were evaluated (92 of 94 in the ANCS group, 81 of 92 in the unexposed group). All the subjects provided urine specimens and 120 provided blood specimens. More detailed information on materials and methods, including specific inclusion and exclusion criteria, have been published previously (32). The Wake Forest School of Medicine and Forsyth Medical Center Institutional Review Boards approved the study. We obtained informed consent from parents or legal guardians and assent from participants.

\section{Data Collection}

Perinatal characteristics were recorded from medical records and research databases. We recorded the presence of maternal hypertension during pregnancy (maternal HTN) and ANCS exposure, defined as maternal treatment with betamethasone and/or dexamethasone (one subject's mother received dexamethasone only and one subject's mother received both betamethasone and dexamethasone). Birth characteristics were noted, including (i) sex, (ii) GA, and (iii) birth weight. Birth weight $\mathrm{z}$-score was determined (33). We categorized subjects as born small for gestational age (SGA) if their birth weight percentile was less than or equal to the $10 \%$ (34). Demographic information was recorded at $14 \mathrm{y}$ of age, including parental-reported race (black vs. non-black), and height, weight, and waist circumference were measured. We calculated BMI $\left(\mathrm{kg} / \mathrm{m}^{2}\right)$ and waist-to-height ratio, and defined overweight/ obese as BMI $\geq 85 \%$ for age and sex (35). Sexual maturity was rated (1 to 5) using a self-reported questionnaire completed in private and was summarized as the average of both determinants of secondary sexual 
characteristics (external genitalia development and pubic hair in males; breast development and pubic hair in females) (36). Resting blood pressure was measured with a mercury manometer after the subject was seated quietly for at least $5 \mathrm{~min}$, and the average of three measurements was recorded according to established guidelines (37). Blood pressure $\mathrm{z}$-scores were calculated (38).

\section{Laboratory Measurements}

Blood was collected from participants in the seated position to measure plasma renin activity, aldosterone, Ang-(1-7), and Ang II. A spot urine sample was provided to measure Ang-(1-7), Ang II, and creatinine. We calculated ARR, the Ang II/Ang-(1-7) ratio in the plasma and urine, and the urinary Ang-(1-7) and Ang II concentrations corrected for creatinine. Specific laboratory methods have been published previously (39).

\section{Statistical Analyses}

Distributions of continuous variables were described with the mean and $S D$ or the median and IQR. We used natural logarithmic transformation to improve the distributional characteristics of the continuous variables when appropriate. Values below the minimum detectable thresholds were assigned one-half those threshold values (39). For between-group comparisons of continuous variables, we used the $t$-test and Wilcoxon Rank-Sum test; for comparisons of categorical variables, we used the Chi-square and Fisher's Exact tests. Correlations were assessed with Pearson or Spearman correlation coefficients.

We used general linear regression models to evaluate the relationship of ANCS exposure and RAAS outcomes. We evaluated effect modification using product terms (ANCS $\times$ modifier). To identify variables that might confound the ANCS-RAAS relationships, we evaluated bivariate relationships between each potential confounder and ANCS and each potential confounder and RAAS outcome. Potential confounders were included in the multivariate models if either of the following were found: (i) an association with both the RAAS measure and ANCS at $P<0.2$, or (ii) a $>10 \%$ change in the regression coefficient for ANCS estimated with general linear models. In addition, sex, race, and maternal HTN were identified a priori as potential confounders and effect modifiers, based on the results of previous studies $(39,40)$. The criterion for inclusion in the final multivariate model was $P<0.05$. For comparisons of the ANCS-exposed and unexposed groups, a two-sided $\alpha$ of 0.05 was considered statistically significant. We used Enterprise Guide software, Version 7.11 of the SAS System for Windows (SAS Institute, Cary, NC) for all analyses.

\section{ACKNOWLEDGMENTS}

We thank the participants and their families, Patricia Brown, RN, research nurse, and Alice Scott, RN, research study coordinator.

\section{STATEMENT OF FINANCIAL SUPPORT}

This study is funded by the Eunice Kennedy Shriver National Institute of Child Health and Human Development (PO1 HD047584; HD084227), the Clinical Research Unit of Wake Forest Baptist Medical Center (MCRR/NIH MO1-RR07122), and the Forsyth Medical Center and Wake Forest School of Medicine Department of Pediatrics research funds.

Disclosure: The authors have no conflicts of interest relevant to this article to disclose.

\section{REFERENCES}

1. Liggins GC, Howie RN. A controlled trial of antepartum glucocorticoid treatment for prevention of the respiratory distress syndrome in premature infants. Pediatrics 1972;50:515-25.

2. Doran TA, Swyer P, MacMurray B, et al. Results of a double-blind controlled study on the use of betamethasone in the prevention of respiratory distress syndrome. Am J Obstet Gynecol 1980;136:313-20.

3. Gilstrap LC, Christensen R, Clewell WH, et al. Effect of corticosteroids for fetal maturation on perinatal outcomes: NIH consensus development panel on the effect of corticosteroids for fetal maturation on perinatal outcomes. JAMA 1995; 273:413-418.

4. Benediktsson R, Lindsay RS, Noble J, Seckl JR, Edwards CR. Glucocorticoid exposure in utero: new model for adult hypertension. Lancet 1993;341:339-41.
5. Dodic M, May CN, Wintour EM, Coghlan JP. An early prenatal exposure to excess glucocorticoid leads to hypertensive offspring in sheep. Clin Sci (Lond) 1998;94:149-55.

6. Shaltout HA, Figueroa JP, Rose JC, Diz DI, Chappell MC. Alterations in circulatory and renal angiotensin-converting enzyme and angiotensinconverting enzyme 2 in fetal programmed hypertension. Hypertension 2009;53:404-8.

7. Gwathmey TM, Shaltout HA, Rose JC, Diz DI, Chappell MC. Glucocorticoid-induced fetal programming alters the functional complement of angiotensin receptor subtypes within the kidney. Hypertension 2011;57:620-6.

8. Doyle LW, Ford GW, Davis NM, Callanan C. Antenatal corticosteroid therapy and blood pressure at 14 years of age in preterm children. Clin Sci (Lond) 2000;98:137-42.

9. Kelly BA, Lewandowski AJ, Worton SA, et al. Antenatal glucocorticoid exposure and long-term alterations in aortic function and glucose metabolism. Pediatrics 2012;129:e1282-90.

10. Dessens AB, Haas HS, Koppe JG. Twenty-year follow-up of antenatal corticosteroid treatment. Pediatrics 2000;105:E77.

11. Finken MJJ, Keijzer-Veen MG, Dekker FW, et al. Antenatal glucocorticoid treatment is not associated with long-term metabolic risks in individuals born before 32 weeks of gestation. Arch Dis Child Fetal Neonatal Ed 2008;93:F442-F447.

12. Dalziel SR, Walker NK, Parag V, et al. Cardiovascular risk factors after antenatal exposure to betamethasone: 30 -year follow-up of a randomised controlled trial. Lancet 2005;365:1856-62.

13. Carbone GM, Sheikh AU, Rogers S, Brewer G, Rose JC. Developmental changes in renin gene expression in ovine kidney cortex. Am J Physiol 1993;264(3 Pt 2):R591-6.

14. Woods LL, Rasch R. Perinatal ANG II programs adult blood pressure, glomerular number, and renal function in rats. Am J Physiol 1998;275(5 Pt 2):R1593-9.

15. Xue H, Zhou L, Yuan P, et al. Counteraction between angiotensin II and angiotensin-(1-7) via activating angiotensin type I and Mas receptor on rat renal mesangial cells. Regul Pept 2012;177:12-20.

16. Benter IF, Yousif MH, Anim JT, Cojocel C, Diz DI. Angiotensin-(1-7) prevents development of severe hypertension and end-organ damage in spontaneously hypertensive rats treated with L-NAME. Am J Physiol Heart Circ Physiol 2006;290:H684-91.

17. Benter IF, Yousif MH, Dhaunsi GS, Kaur J, Chappell MC, Diz DI. Angiotensin-(1-7) prevents activation of NADPH oxidase and renal vascular dysfunction in diabetic hypertensive rats. Am J Nephrol 2008;28:25-33.

18. Chappell MC, Marshall AC, Alzayadneh EM, Shaltout HA, Diz DI. Update on the Angiotensin converting enzyme 2-Angiotensin (1-7)-MAS receptor axis: fetal programing, sex differences, and intracellular pathways. Front Endocrinol (Lausanne) 2014;4:201.

19. Ferrario CM, Chappell MC, Tallant EA, Brosnihan KB, Diz DI. Counterregulatory actions of angiotensin-(1-7). Hypertension 1997;30(3 Pt 2):535-41.

20. Simões e Silva AC, Diniz JSS, Pereira RM, Pinheiro SVB, Santos RAS. Circulating renin angiotensin system in childhood chronic renal failure: marked increase of angiotensin-(1-7) in end-stage renal disease. Pediatr Res 2006; 60:734-739.

21. Allred AJ, Chappell MC, Ferrario CM, Diz DI. Differential actions of renal ischemic injury on the intrarenal angiotensin system. Am J Physiol Renal Physiol 2000;279:F636-45.

22. Xiao F, Hiremath S, Knoll G, et al. Increased urinary angiotensin-converting enzyme 2 in renal transplant patients with diabetes. PLoS One 2012;7:e37649.

23. Kasper SO, Basso N, Kurnjek ML, et al. Divergent regulation of circulating and intrarenal renin-angiotensin systems in response to long-term blockade. Am J Nephrol 2005;25:335-41.

24. Bi J, Contag SA, Carey LC, et al. Antenatal betamethasone exposure alters renal responses to angiotensin-(1-7) in uninephrectomized adult male sheep. J Renin Angiotensin Aldosterone Syst 2013;14:290-8.

25. Contag SA, Bi J, Chappell MC, Rose JC. Developmental effect of antenatal exposure to betamethasone on renal angiotensin II activity in the young adult sheep. Am J Physiol Renal Physiol 2010;298:F847-56. 
26. Dilauro M, Zimpelmann J, Robertson SJ, Genest D, Burns KD. Effect of ACE2 and angiotensin-(1-7) in a mouse model of early chronic kidney disease. Am J Physiol Renal Physiol 2010;298:F1523-32.

27. Vieux R, Fresson J, Guillemin F, Hascoet JM. Perinatal drug exposure and renal function in very preterm infants. Arch Dis Child Fetal Neonatal Ed 2011;96:F290-F295.

28. Epelman S, Shrestha K, Troughton RW, et al. Soluble angiotensin-converting enzyme 2 in human heart failure: relation with myocardial function and clinical outcomes. J Card Fail 2009;15:565-71.

29. Yamaleyeva LM, Gilliam-Davis S, Almeida I, Brosnihan KB, Lindsey SH, Chappell MC. Differential regulation of circulating and renal ACE2 and ACE in hypertensive mRen2.Lewis rats with early-onset diabetes. Am J Physiol Renal Physiol 2012;302:F1374-84.

30. Engeli S, Böhnke J, Gorzelniak K, et al. Weight loss and the renin-angiotensin-aldosterone system. Hypertension 2005;45:356-62.

31. Underwood PC, Adler GK. The renin angiotensin aldosterone system and insulin resistance in humans. Curr Hypertens Rep 2013;15:59-70.

32. Washburn L, Nixon P, Russell G, Snively BM, O'Shea TM. Adiposity in adolescent offspring born prematurely to mothers with preeclampsia. J Pediatr 2013;162:912-7.e1.

33. Oken E, Kleinman KP, Rich-Edwards J, Gillman MW. A nearly continuous measure of birth weight for gestational age using a United States national reference. BMC Pediatr 2003;3:6.
34. Battaglia FC, Lubchenco LO. A practical classification of newborn infants by weight and gestational age. J Pediatr 1967;71:159-63.

35. Barlow SE; Expert Committee. Expert committee recommendations regarding the prevention, assessment, and treatment of child and adolescent overweight and obesity: summary report. Pediatrics 2007;120 Suppl 4:S164-92.

36. Taylor SJ, Whincup PH, Hindmarsh PC, Lampe F, Odoki K, Cook DG. Performance of a new pubertal self-assessment questionnaire: a preliminary study. Paediatr Perinat Epidemiol 2001;15:88-94.

37. Update on the 1987 Task Force Report on High Blood Pressure in Children and Adolescents: A working group report from the National High Blood Pressure Education Program. National High Blood Pressure Education Program Working Group on Hypertension Control in Children and Adolescents. Pediatrics 1996;98 (4 Pt 1):649-58.

38. Rosner B, Cook N, Portman R, Daniels S, Falkner B. Determination of blood pressure percentiles in normal-weight children: some methodological issues. Am J Epidemiol 2008;167:653-66.

39. Washburn LK, Brosnihan KB, Chappell MC, et al. The renin-angiotensinaldosterone system in adolescent offspring born prematurely to mothers with preeclampsia. J Renin Angiotensin Aldosterone Syst 2015;16: 529-38.

40. Miller JA, Anacta LA, Cattran DC. Impact of gender on the renal response to angiotensin II. Kidney Int 1999;55:278-85. 